\title{
Natural and surgical history of Chiari malformation Type I in the pediatric population
}

\author{
I. Jonathan Pomeraniec, BSc, ${ }^{1}$ Alexander Ksendzovsky, MD,,2 Ahmed J. Awad, MD,1 \\ Francis Fezeu, MD, PhD, ${ }^{1}$ and John A. Jane Jr., MD
}

'Department of Neurological Surgery, University of Virginia Health Sciences Center, Charlottesville, Virginia; and ${ }^{2}$ Surgical Neurology Branch, National Institutes of Neurological Disorders and Stroke, National Institutes of Health, Bethesda, Maryland

OBJECTIVE The natural and surgical history of Chiari malformation Type I (CM-I) in pediatric patients is currently not well described. In this study the authors discuss the clinical and radiological presentation and outcomes in a large cohort of pediatric CM-I patients treated with either conservative or surgical management.

METHODS The authors retrospectively reviewed 95 cases involving pediatric patients with CM-I who presented between 2004 and 2013. The patients ranged in age from 9 months to 18 years (mean 8 years) at presentation. The cohort was evenly split between the sexes. Twenty-five patients underwent posterior fossa decompression (PFD) with either dural splitting or duraplasty. Seventy patients were managed without surgery. Patients were followed radiologically (mean 44.8 months, range 1.2-196.6 months) and clinically (mean 66.3 months, range 1.2-106.5 months).

RESULTS Seventy patients were treated conservatively and followed with serial outpatient neurological and radiological examinations, whereas 25 patients were treated with PFD. Of these 25 surgical patients, 11 were treated with duraplasty (complete dural opening) and 14 were treated with a dura-splitting technique (incomplete dural opening). Surgical intervention was associated with better clinical resolution of symptoms and radiological resolution of tonsillar ectopia and syringomyelia ( $p=0.0392)$. Over the course of follow-up, $20(41.7 \%)$ of 48 nonsurgical patients who were symptomatic at presentation experienced improvement in symptoms and 18 (75\%) of 24 symptomatic surgical patients showed clinical improvement $(p=0.0117)$. There was no statistically significant difference in resolution of symptoms between duraplasty and dura-splitting techniques $(p=0.3572)$ or between patients who underwent tonsillectomy and tonsillopexy $(p=$ 0.1667). Neither of the 2 patients in the conservative group with syrinx at presentation showed radiological evidence of resolution of the syrinx, whereas $14(87.5 \%)$ of 16 patients treated with surgery showed improvement or complete resolution of syringomyelia $(p=0.0392)$. In the nonsurgical cohort, 3 patients $(4.3 \%)$ developed new or increased syrinx.

CONCLUSIONS The overwhelming majority of CM-I patients $(92.9 \%)$ managed conservatively do not experience clinical or radiological progression, and a sizeable minority $(41.7 \%)$ of those who present with symptoms improve. However, appropriately selected symptomatic patients (sleep apnea and dysphagia) and those presenting with syringomyelia should be considered surgical candidates because of the high rates of clinical (75\%) and radiological improvement (87.5\%).

http://thejns.org/doi/abs/10.3171/2015.7.PEDS1594

KEY WORDS Chiari malformation; syringomyelia; pediatric neurosurgery; natural history

$\mathrm{C}$ HIARI malformation Type I (CM-I) represents a significant clinical burden among children. ${ }^{29}$ Once presumed a disease of adolescence and childhood, with the medical community's increased propensity to perform diagnostic imaging, CM-I has recently become recognized in younger children. Typically, tonsillar herniation of $5 \mathrm{~mm}$ below the foramen magnum is the cutoff for radiological diagnosis. ${ }^{27}$ Symptoms associated with CM-I are believed to result from compression of neural struc- tures in the posterior fossa and can also be associated with a syrinx in the spinal cord or brainstem. ${ }^{30}$ While adults most commonly present with posterior headaches and/or neck pain, children can have more occult findings such as ataxia, sensory and motor deficits, lower cranial nerve abnormalities, or merely irritability or neck arching. ${ }^{6}$

The natural history of CM-I remains poorly understood, as most reported pediatric series describe outcomes in patients treated with either surgery or conservative

ABBREVIATIONS CM-I = Chiari malformation Type I; PFD = posterior fossa decompression; PFDD = PFD with duraplasty.

SUBMITTED February 10, 2015. ACCEPTED July 13, 2015.

INCLUDE WHEN CITING Published online November 20, 2015; DOI: 10.3171/2015.7.PEDS1594. 
management alone. One of the larger retrospective series in 2011 by Benglis et al. reviewed outcomes in a 124 (43 asymptomatic and 81 symptomatic at presentation) conservatively managed pediatric CM-I patients who were followed radiologically. The authors found that the majority of patients did not progress clinically or radiologically, and no new neurological deficits were observed during a mean follow-up period of 2.83 years. ${ }^{6}$ Another analysis by Strahle et al. in 2011 found that the majority of 147 pediatric patients with CM-I, who were also managed conservatively, tended to have a benign natural history over the course of clinical and MRI follow-up, with a mean duration of 4.6 and 3.8 years, respectively. ${ }^{31}$

According to recent literature, surgery is typically offered to asymptomatic patients only with a high degree of herniation and/or a large syrinx. Without a widely recognized, definitive correlation between magnitude of tonsillar herniation and clinical manifestations of cervicomedullary junction compression, debate lingers over the indications for operative versus nonoperative management of CM-I. $1,2,5,6,25,39$ This is especially true for those patients with mild or no symptoms. ${ }^{1,2,5,25}$ As such, there are no generally accepted criteria for selecting patients with CM-I for surgical treatment, and the decision for suboccipital decompression for symptomatic relief can be subjective. ${ }^{37}$ In this study, we analyzed a cohort of patients with CM-I who have been managed at the University of Virginia over the last 10 years. These patients were either treated with surgery or managed conservatively. All were followed clinically and with serial MRI. Subtle differences in surgical technique may have affected outcome within the surgically treated cohort.

To our knowledge, there are no prior studies comparing relatively large surgical and nonsurgical cohorts with longterm clinical and radiological follow-up. Thus, the indications for surgical management of CM-I remain undefined. Furthermore, there is a dearth of literature describing and comparing the nuances of posterior fossa decompression (PFD). In the present study, we compare surgical and conservative management of CM-I and define strict criteria for surgical decompression. This study will serve to further understanding of the natural history of CM-I as well as to help identify the appropriate surgical candidate based on clinical symptoms and radiological findings.

\section{Methods \\ Patient Population}

After obtaining institutional review board approval, the authors retrospectively reviewed 116 consecutive cases involving pediatric patients between the ages of 9 months and 18 years (mean 8 years) who were diagnosed with CM-I (defined as involving herniation of the cerebellar tonsils at least $5 \mathrm{~mm}$ below the foramen magnum) between 2004 and 2013 at the University of Virginia. Twenty-one patients were excluded from analysis due to lack of followup from initial evaluation or operation by a different primary neurosurgeon. One of the patients excluded from the study presented with tonsillar herniation of $4.3 \mathrm{~mm}$ and worsening symptoms with an abnormal cine MRI study. Ninety-five patients were included in the final analysis.
All patients included in this study were evaluated and followed by a single pediatric neurosurgeon who was also the primary surgeon for all patients who underwent surgical decompression. Seventy patients were treated conservatively and followed in the outpatient setting. Twentyfive patients (26.3\% of the total study group) underwent primary surgical decompression for symptomatic CM-I. Surgical patients were subdivided into 2 groups: patients who underwent PFD with dural splitting $(\mathrm{n}=14)$ and a second group who underwent duraplasty $(\mathrm{n}=11)$. Imaging findings, symptoms, and findings on neurological examinations were noted at presentation and for the duration of follow-up, and these findings were analyzed.

\section{Clinical Evaluation}

Patients underwent comprehensive multidisciplinary evaluation including child neurology, sleep specialist, and otolaryngology consultations, with information made available regarding history, neurological examinations, polysomnography data, vocal cord mobility, upper airway motor dysfunction, and swallowing difficulty. All patients were evaluated by the same pediatric neurosurgeon (J.A.J.), who was also the primary operating surgeon in all cases. Preoperative and postoperative neurological examinations were performed during inpatient hospitalizations and outpatient clinical visits.

\section{Imaging}

Patients underwent high-resolution MRI using standard T1- and T2-weighted spin-echo sequences. Imaging studies were independently reviewed at diagnosis by a neuroradiologist and the neurosurgeon evaluating the patient. We recorded imaging characteristics consistent with CM-I, including amount of cerebellar tonsillar ectopia, CSF flow dynamics at the foramen magnum, as well as the presence of spinal cord syringomyelia. We defined a syrinx as a contiguous fluid collection (hypointense on T1weighted images with corresponding $\mathrm{T} 2$ hyperintensity) of at least $2 \mathrm{~mm}$ in maximum anteroposterior diameter on sagittal or axial imaging, suggesting fluid within the spinal cord. If a syrinx was present, we noted its widest diameter in millimeters as viewed on sagittal imaging and its length according to number of spanning vertebral levels (Fig. 1). Presyrinx states (T2 hyperintensity with indistinct $\mathrm{T} 1$ prolongation and without cavitation) were separately classified. We compared baseline imaging parameters to findings on postoperative imaging. If a patient had multiple MRI studies, we considered only those studies performed at the time of CM-I diagnosis. We considered the most recent imaging in nonsurgical patients or the MRI studies performed immediately preceding surgery in surgical patients.

\section{Evaluation of CSF Flow}

CSF flow at the foramen magnum was evaluated by cine MRI obtained in 74 patients at the time of CM-I diagnosis (51 patients in the nonsurgical group, 23 patients in the surgical group). Sagittal CSF flow studies at the craniocervical junction evaluated for CSF pulsations across the anterior and posterior midline foramen magnum as 

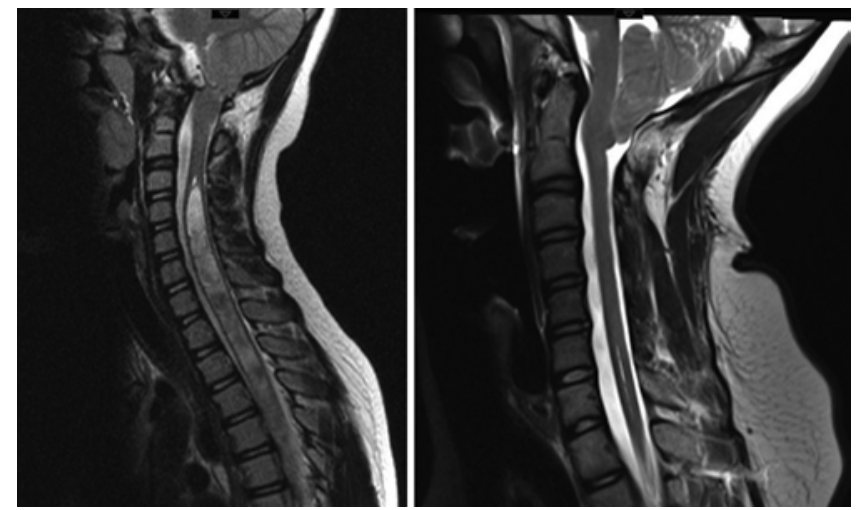

FIG. 1. T2-weighted sagittal MR images of cervical spine obtained in a child who presented with dysphagia showing a syrinx extending from $\mathrm{C} 4$ into the thoracic spine before (left) and after (right) resolution following a dura-splitting procedure.

well as for any abnormally exaggerated cranial or caudal pulsations of the lower brainstem, upper cervical cord, or cerebellar tonsils.

\section{Sleep Evaluation}

Patients with suspected sleep-related breathing disorders were evaluated in the University of Virginia Sleep Disorders Laboratory. Standard testing consisted of electroencephalography derivations C3/A2, C2/A1, O1/ $\mathrm{A} 2, \mathrm{O} 2 / \mathrm{A} 1$, electromyography (chin), electrooculography (right/left), electrocardiography, and oxygen saturation by digital pulse oximetry, nasal/oral airflow by thermistor or nasal pressure cannula, end-tidal $\mathrm{CO}_{2}$ by nasal cannula, and qualitative thoracic/abdominal movement by respiratory inductive plethysmography. Natural sleep was observed overnight. No sedation was administered. Central apneas, obstructive apneas, hypopneas, periodic breathing, the adequacy of gas exchange, and heart rate were recorded during sleep.

\section{Operative Procedure}

Twenty-five patients underwent PFD procedures. Foramen magnum decompression was performed, measuring a minimum of $2 \mathrm{~cm}$ wide and $2 \mathrm{~cm}$ above the foramen. C-I laminectomy was performed in most patients, and a C-2 laminectomy was performed in those patients whose tonsils extended to that level. For those patients who underwent duraplasty, the dura was opened in a full-thickness fashion, with an initial attempt to maintain an intact arachnoid layer. Some patients underwent partial tonsillar resection, some had their cerebellar tonsils cauterized, and in some patients, the cerebellar tonsils remained untouched. For tonsillectomy, dissection was taken circumferentially around the tonsils, which were subsequently elevated with careful dissection. The inferior portions of the tonsils were cauterized, incised, and internally debulked. For tonsillopexy, tonsils were mobilized from below the level of the dural opening and subsequently cauterized superiorly with bipolar electrocautery. For duraplasty with tonsils untouched, the tonsils themselves were not scarred down and careful dissection was taken between and be-

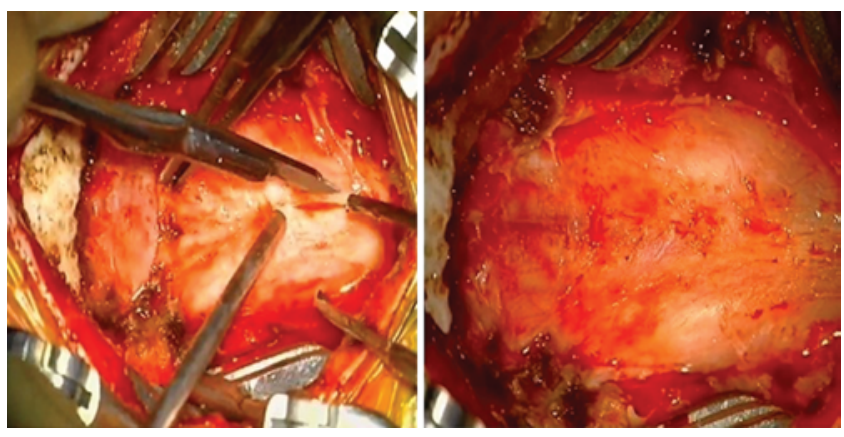

FIG. 2. Intraoperative photographs showing the dura-splitting technique. Left: Photograph showing the dura split down to the thick dural band across C-1 (leftmost side of image). Right: Photograph showing thinned dura with underlying tonsils. Figure is available in color online only.

neath the tonsils. A fashioned piece of artificial dura (DuraGen or Durepair) was used for the duraplasty and tacked into place. A central tacking suture was placed in the dural graft through the fascia or muscle to avoid adherence of the dural graft to underlying arachnoid. The dural graft was covered with DuraSeal or Gelfoam, and the closure was performed in standard layered fashion. For those who underwent dural splitting, the superficial layer of the dura was split and opened without completely cutting through the inferior layer until the dura was translucent (Fig. 2). The dural band at the foramen magnum was released. Intraoperative ultrasound was performed before and after duraplasty and/or dural splitting, but in no case was a planned dura-splitting technique converted to a duraplasty on the basis of ultrasound.

\section{Statistical Analysis}

Statistical significance calculations were obtained using ANOVA and the chi-square test. Categorical variables were compared using Fisher's exact test. Specific statistical analyses as defined in the text were performed using Microsoft Excel (Microsoft Corp.) and GraphPad Prism software (GraphPad Software). For all statistical tests, a $p$ value $<0.05$ was considered significant.

\section{Results \\ Patient Characteristics}

Seventy patients were treated conservatively and 25 patients received PFD. Mean age at presentation was $8.3 \pm$ 5.3 years. The cohort had a roughly even number of males $(n=47)$ and females $(n=48)$, with 14 males and 11 females treated surgically. The mean duration of MRI follow-up was 44.8 months (range 1.2-196.6 months) and clinical follow-up was 66.3 months (range 1.2-106.5 months) (Table 1). Mean tonsillar herniation below the foramen magnum at presentation was $12.6 \mathrm{~mm}$ (range $4.3-37.0 \mathrm{~mm}$ ). On average, the nonsurgical group exhibited less tonsillar herniation (mean $10.4 \mathrm{~mm}$ ) than the surgical group (mean $18.8 \mathrm{~mm}$ ) at presentation (Table 2). Across all surgical patients, preoperative tonsillar descent ranged from 8.0 to $37.0 \mathrm{~mm}$. 
TABLE 1. Patient demographic characteristics and follow-up stratified by management

\begin{tabular}{lcccc}
\hline \multicolumn{1}{c}{ Management } & $\mathrm{M}, \mathrm{F}(\mathrm{n})$ & Age at Presentation* & Clinical FU† & MRI FU† \\
\hline Nonsurgical & 33,37 & $7.6 \pm 4.9$ & $69.3 \pm 24.3$ & $38.9 \pm 31.8$ \\
\hline Surgical & 14,11 & $10.2 \pm 5.9$ & $58.2 \pm 29.7$ & $60.8 \pm 31.2$ \\
\hline \multicolumn{1}{c}{ Duraplasty } & 6,5 & $9.8 \pm 6.1$ & $75.5 \pm 22.2$ & $80.0 \pm 24.3$ \\
\hline \multicolumn{1}{c}{ Dural splitting } & 8,6 & $10.9 \pm 5.4$ & $44.6 \pm 28.3$ & $45.8 \pm 28.1$ \\
\hline $\begin{array}{l}\text { FU }=\text { follow-up. } \\
\text { * Mean age in years } \pm \text { SD. } \\
\dagger \text { Mean follow-up length in months } \pm \text { SD. }\end{array}$ & & & \\
\end{tabular}

\section{Presenting Symptoms}

Of 95 total patients, 70 patients presented with Chiarirelated symptoms. Forty-eight patients (69\%) in the nonsurgical group and 22 patients (88\%) in the surgical group presented with symptoms including visual disturbance, suboccipital headaches, headaches worsened with Valsalva maneuver, sensorimotor deficits, and nausea/vomiting. Fifty-nine patients experienced headache, including 40 in the nonsurgical group and 19 in the surgical group. Some patients had more than 1 presenting symptom, and the most common combinations of symptoms included headache (headache + visual disturbance in 6 patients, headache + sensorimotor symptoms in 5 patients, headache + swallowing difficulties in 4 patients, and headache + nausea/vomiting in 4 patients) (Table 3 ).

Twenty-five patients were either asymptomatic or found to have CM-I as an incidental finding during workup for an unrelated diagnosis. In the surgical group, 3 patients presented incidentally (1 during workup for short stature, another during evaluation for seizures and developmental delay, and 1 on evaluation for congenital obstructive hydrocephalus). All of these patients were followed and subsequently found to have expansile syrinx on radiological imaging. In the nonsurgical group, 22 patients presented without symptoms related to Chiari but were found to have Chiari malformation on radiological imaging. The most common reasons for neurosurgical workup of these patients included seizures $(n=7)$ and developmental delay $(n=6)$. Other reasons for workup included evaluation for scoliosis and hyperreflexia, surveillance imaging for neurofibromatosis Type 1 , and pituitary insufficiency.
In the surgical group, 16 patients $(64 \%)$ presented with a syrinx and 21 patients $(84 \%)$ presented with either a syrinx or central sleep apnea. Four patients did not present with either syrinx or sleep apnea. Three of these patients experienced dysphagia. Two patients experienced headache and dysphagia, 1 of whom exhibited tonsillar herniation of $10.4 \mathrm{~mm}$ and the other exhibited $30.3 \mathrm{~mm}$ herniation on imaging. Another patient experienced dysphagia and exhibited tonsillar herniation of $27.1 \mathrm{~mm}$ on imaging. The fourth patient experienced headache and sensorimotor disturbance and exhibited tonsillar herniation of 13.6 $\mathrm{mm}$ on imaging. In total, 6 patients were discovered to have abnormal findings on neurological examination.

\section{Surgical Outcomes}

Surgical intervention was associated with better resolution of symptoms. Twenty (42\%) of 48 nonsurgical patients who were symptomatic at presentation experienced improvement in symptoms versus $18(75 \%)$ of 24 surgical patients $(\mathrm{p}=0.0117)$. There was no significant difference of symptom outcomes between duraplasty and dura-splitting techniques $(\mathrm{p}=0.3572)$ or between tonsillectomy and tonsillopexy $(\mathrm{p}=0.1667)$ (Table 4).

All patients treated with duraplasty-tonsillectomy showed symptomatic improvement. Of 5 patients treated with duraplasty-tonsillopexy, only 2 showed symptomatic improvement. For the 2 patients with tonsils untouched, 1 showed symptomatic improvement while the other did not (Table 5).

In the surgical group, 7 patients presented with central

TABLE 2. Tonsillar descent below foramen magnum across all patients and surgical patients grouped by PFD technique*

\begin{tabular}{|c|c|c|c|c|c|c|c|c|c|}
\hline \multirow[b]{2}{*}{$\begin{array}{l}\text { Herniation } \\
\text { Below FM }\end{array}$} & \multicolumn{4}{|c|}{ Management } & \multicolumn{5}{|c|}{ Surgical Procedure } \\
\hline & Nonsurgical & Surgical & $\begin{array}{l}\text { Surgical (excluding } \\
\text { tonsillectomy) }\end{array}$ & Total & DPL & $\begin{array}{c}\text { DPL } \\
\text { Tonsillectomy }\end{array}$ & $\begin{array}{c}\text { DPL } \\
\text { Tonsillopexy }\end{array}$ & $\begin{array}{l}\text { DPL Tonsils } \\
\text { Untouched }\end{array}$ & $\begin{array}{c}\text { Dural } \\
\text { Splitting }\end{array}$ \\
\hline Mean \pm SD & $10.4 \pm 4.9$ & $18.8 \pm 8.3$ & $18.3 \pm 7.7$ & $12.6 \pm 7.0$ & & & & & \\
\hline Most recent & 9.4 & 8.4 & 9.9 & 9.1 & & & & & \\
\hline Preop & & & & & 17.8 & 21.4 & 16.5 & 13.5 & 20.5 \\
\hline Postop & & & & & 5.8 & 0.0 & 11.1 & 3.9 & 11.0 \\
\hline Most recent & & & & & 5.8 & 0.0 & 11.2 & 3.9 & 11.0 \\
\hline Mean difference & -1.1 & $-10.3 \dagger$ & $-8.3 \ddagger$ & -3.6 & -12.0 & -21.4 & -5.4 & -9.6 & -9.0 \\
\hline
\end{tabular}


TABLE 3. Clinical presentations of 70 symptomatic patients with $\mathrm{CM}-\mathrm{I}^{*}$

\begin{tabular}{lcc}
\hline Symptom at Presentation & Nonsurgical & Surgical \\
\hline Any headache & 40 & 19 \\
\hline Suboccipital headache & 17 & 12 \\
\hline Valsalva headache & 9 & 5 \\
\hline Swallowing difficulty & 7 & 8 \\
\hline Nausea/vomiting & 7 & 1 \\
\hline Sleep apnea & 1 & 7 \\
\hline Sensory complaints/deficits & 2 & 5 \\
\hline Motor deficits & 3 & 3 \\
\hline Asymptomatic/incidental & 22 & 3 \\
\hline
\end{tabular}

* Values are number of patients. Some patients presented with more than 1 symptom.

sleep apnea. Overall, 5 (71.4\%) of 7 patients experienced resolution of sleep apnea. All 3 of the patients who underwent duraplasty experienced resolution of sleep apnea, whereas $2(50 \%)$ of 4 patients who underwent dural splitting experienced resolution $(\mathrm{p}=0.4286)$. This difference did not reach significance, likely due to the relatively low number of patients. Two patients in the dura-splitting group experienced minimal improvement postoperatively and required positive airway pressure as of their most recent follow-up.

\section{Radiological Outcomes}

\section{Tonsillar Herniation}

There was a significant difference of reduction in tonsillar herniation between nonsurgical $(1.1 \mathrm{~mm})$ and surgical $(10.3 \mathrm{~mm})$ patients $(\mathrm{p}<0.0001)$, which was further elucidated when excluding patients who underwent tonsillectomy (mean reduction of $8.3 \mathrm{~mm}, \mathrm{p}<0.0001$ ) (Table 2).

\section{Syrinx}

Eighteen patients had a syrinx at presentation. Sixteen of these patients were treated with surgery (7 duraplasty, 9 dural splitting) and 2 patients were managed conservatively (1 patient had a stable syrinx without associated symptoms, and 1 patient opted for conservative management due to abnormal skull base development). All patients with a syrinx underwent at least 1 repeat MRI study of the spine (Fig. 1).

Radiological improvement or resolution was observed in zero ( $0 \%$ ) of 2 nonsurgical patients versus $14(87.5 \%)$ of 16 surgical patients $(p=0.0392)$ (Table 6). There was no difference in syrinx resolution between duraplasty $(71.4 \%)$ and dural splitting $(100 \%)(\mathrm{p}=0.1750)$. Of note, 2 patients who received tonsillopexy experienced expansile syrinx after surgery and underwent repeat surgery ( 1 of these patients also experienced persistent headaches). One of these patients experienced improvement in syrinx after repeat tonsillopexy while the other remained unchanged.

New or increased syrinx was observed in 3 patients in the nonsurgical group and 4 patients in the surgical group. Of the 4 patients in the surgical group, 2 patients exhibited increased syrinx, 1 patient exhibited increased syrinx
TABLE 4. Resolution of symptoms based on type of management and procedure*

\begin{tabular}{lccc}
\hline \multicolumn{1}{c}{ Management } & Improved/Resolved & Not Improved & p Value \\
\hline Nonsurgical & $20(41.7)$ & $28(58.3)$ & \\
\cline { 1 - 3 } Surgical $\dagger$ & $18(75.0)$ & $6(25.0)$ & \\
\cline { 1 - 3 } Duraplasty & $7(63.6)$ & $4(36.4)$ & \multirow{2}{*}{0.3572} \\
\cline { 1 - 3 } Dura splitting $\dagger$ & $11(84.6)$ & $2(15.4)$ & \\
\hline
\end{tabular}

* Values are number of patients (\%).

$\dagger$ Not including 1 asymptomatic patient who underwent the dural splitting procedure for increased syrinx following endoscopic third ventriculostomy for congenital obstructive hydrocephalus.

$\ddagger$ Bold type indicates statistical significance.

that eventually stabilized after redo decompression, and 1 patient exhibited a new syrinx of the cervical cord after resolution of a thoracic syrinx. Presyrinx was observed in zero nonsurgical patients and 3 surgical patients (1 case of which resolved).

Combining syrinx at presentation with new or increased syrinx developed over follow-up, there were in total 5 nonsurgical and 20 surgical patients with a syrinx. Resolution was observed in $0(0 \%)$ of 5 nonsurgical patients versus well over half of surgical patients $(65 \%)(\mathrm{p}=0.0149)$.

Of 16 surgical patients with symptomatic syrinx at presentation, 11 patients $(68.8 \%)$ showed improvement in symptoms and 5 patients (31.2\%) showed worsening symptoms. All 11 patients (100\%) with improved symptoms also exhibited decreased syrinx size. Of the 5 patients who did not show symptomatic improvement, 3 patients $(60 \%)$ exhibited improved syrinx and 2 exhibited worsened syrinx $(p=0.0833)$. Of the 2 nonsurgical patients with a syrinx at presentation, 1 patient experienced no change in symptoms (motor) while the other patient improved (headache only).

\section{CSF Flow}

Of patients who underwent cine MRI studies, 33 (64.7\%) of 51 patients in the nonsurgical group exhibited abnormal CSF flow versus 21 (91.3\%) of 23 in the surgical group ( $\mathrm{p}=$ 0.0227). Surgery improved CSF flow in $60 \%$ of patients $(p=0.05)$. Of note, no patients in the surgical cohort exhibited worsened CSF flow dynamics following decompression (Table 7). A change in CSF flow analysis was not used as a surgical indication in this series of patients.

\section{Postoperative Complications}

Postoperative complications were noted during the immediate postoperative period during hospitalization and included poor feeding, neck spasms, neck pain, and residual sleep apnea, but none of these were found to be associated with a particular surgical technique. One patient who had a history of sleep apnea underwent PFD with duraplasty (PFDD) and tonsillectomy and had initially recovered well, with an unremarkable postoperative CT scan on the 1st postoperative day. However, 1 day later the patient experienced severe posterior fossa swelling and sleep apnea requiring intubation, tracheostomy, and a prolonged intensive care unit and hospital course (71 days including outpatient rehabilitation). MRI revealed 
TABLE 5. Clinical presentation and follow-up for surgical patients

\begin{tabular}{|c|c|c|c|c|c|c|c|c|}
\hline \multirow{2}{*}{$\begin{array}{l}\text { Case } \\
\text { No. }\end{array}$} & \multirow{2}{*}{$\begin{array}{l}\text { Sex, Age at } \\
\text { Op (yrs) }\end{array}$} & \multicolumn{2}{|c|}{ Tonsillar Descent (mm) } & \multirow{2}{*}{$\begin{array}{c}\text { Syrinx at } \\
\text { Presentation }\end{array}$} & \multirow[b]{2}{*}{ Neurological Examination } & \multirow[b]{2}{*}{ Predominant Symptoms } & \multirow[b]{2}{*}{ Management } & \multirow{2}{*}{$\begin{array}{l}\text { Clinica } \\
\text { Course }\end{array}$} \\
\hline & & Preop & Postop & & & & & \\
\hline 1 & $M, 16.4$ & 37.0 & 0.0 & Y & Nystagmus, Romberg & Headache, sleep apnea, motor & $\mathrm{TX}$ & I \\
\hline 2 & $\mathrm{~F}, 14.0$ & 20.0 & 0.0 & Y & $\begin{array}{l}\text { Hyperreflexia, abdominal } \\
\text { reflexes }\end{array}$ & Dysphagia & $\mathrm{TX}$ & 1 \\
\hline 3 & M, 3.2 & 8.0 & 0.0 & Y & Normal & Incidental* $^{*}$ & $\mathrm{TX}$ & I \\
\hline 4 & M, 16.8 & 20.6 & 0.0 & Y & Normal & Headache & $\mathrm{TX}$ & 1 \\
\hline 5 & $F, 11.0$ & 14.0 & 14.6 & Y & Normal & Headache, visual & TPX & W \\
\hline 6 & M, 1.8 & 10.4 & 5.9 & $\mathrm{~N}$ & Normal & Headache, dysphagia & TPX & W \\
\hline 7 & $F, 12.9$ & 16.0 & 12.5 & $\mathrm{~N}$ & Normal & $\begin{array}{l}\text { Visual, headache, sensory, sleep } \\
\text { apnea }\end{array}$ & TPX & 1 \\
\hline 8 & M, 2.2 & 30.3 & 7.4 & $\mathrm{~N}$ & Normal & Headache, dysphagia & TPX & 1 \\
\hline 9 & $F, 16.6$ & 12.0 & 15.3 & Y & Normal & Headache, sensory & TPX & W \\
\hline 10 & $\mathrm{~F}, 4.2$ & 11.0 & 0.0 & Y & Dysmetria, tremor & Headache, motor, dysphagia & TU & W \\
\hline 11 & M, 9.0 & 15.9 & 7.7 & $\mathrm{~N}$ & Palate asymmetry & Headache, sensory, sleep apnea & TU & 1 \\
\hline 12 & M, 17.1 & 31.0 & 38.0 & $\mathrm{~N}$ & Normal & Headache, sleep apnea & DS & I \\
\hline 13 & $\mathrm{~F}, 18.7$ & 29.0 & 8.0 & Y & Normal & $\begin{array}{l}\text { Headache, visual, sensory, } \\
\text { swallowing }\end{array}$ & DS & I \\
\hline 14 & $F, 9.1$ & 15.0 & 13.5 & Y & Normal & Swallowing & DS & I \\
\hline 15 & $\mathrm{~F}, 3.0$ & 27.1 & 9.6 & $\mathrm{~N}$ & Normal & Dysphagia & DS & I \\
\hline 16 & $\mathrm{M}, 11.7$ & 24.0 & 22.0 & $Y$ & Normal & Headache, visual & DS & W \\
\hline 17 & M, 2.5 & 8.0 & 5.0 & Y & $\begin{array}{l}\text { Hypotonia, dysconjugate } \\
\text { gaze }\end{array}$ & Incidental† & DS & I \\
\hline 18 & $\mathrm{M}, 4.8$ & 29.0 & 8.8 & $\mathrm{~N}$ & Normal & $\begin{array}{l}\text { Headache, sleep apnea, dys- } \\
\text { phagia }\end{array}$ & DS & 1 \\
\hline 19 & $F, 12.5$ & 14.0 & 13.0 & Y & Normal & Sleep apnea & DS & 1 \\
\hline 20 & $F, 16.3$ & 21.3 & 4.6 & Y & Normal & Headache & DS & I \\
\hline 21 & $F, 12.8$ & 19.0 & 2.3 & $Y$ & Normal & $\begin{array}{l}\text { Headache, motor, nausea/ } \\
\text { vomiting }\end{array}$ & DS & 1 \\
\hline 22 & M, 16.7 & 13.6 & 11.0 & $\mathrm{~N}$ & Normal & Headache, sensory & DS & 1 \\
\hline 23 & M, 5.6 & 13.0 & 4.1 & Y & Normal & Asymptomatic $\ddagger$ & DS & $\mathrm{NC}$ \\
\hline 24 & $M, 8.0$ & 11.0 & 0.0 & $Y$ & Nystagmus & Headache & DS & W \\
\hline 25 & $M, 13.2$ & 25.0 & 14.4 & $\mathrm{~N}$ & Normal & Headache, sleep apnea & DS & 1 \\
\hline
\end{tabular}

$\mathrm{DS}=$ dural splitting; I = improved; $\mathrm{NC}=$ no change; $\mathrm{N}=$ no; $\mathrm{TPX}=$ tonsillopexy; $\mathrm{TU}=$ tonsils untouched; $\mathrm{TX}=$ tonsillectomy; $\mathrm{W}=$ worsened; $\mathrm{Y}=$ yes

* Incidental finding during workup for short stature.

$\dagger$ Incidental finding during evaluation for seizures.

‡ Increasing syringomyelia after endoscopic third ventriculostomy for congenital hydrocephalus.

acute ischemia/infarction of the residual right cerebellar tonsil as well as edematous changes of the dorsolateral aspect of the caudal medulla. Excluding this patient, the mean length of hospital stay was 3.4 days across all surgical patients (range $2-5$ days), which differed significantly between duraplasty (mean 3.8 days) and dural splitting (mean 3.1 days, $\mathrm{p}=0.0291$ ). Postoperative nausea and/or vomiting was more common in duraplasty (5 of 11) than in dural splitting (2 of 14), but this difference was not significant $(\mathrm{p}=0.1775)$.

\section{Repeat Surgery}

In total, 6 patients exhibited either unchanged or worsening symptoms or radiological progression following PFD. Of these patients, 5 underwent repeat operations.
Of 4 patients who initially underwent tonsillectomy, zero $(0 \%)$ exhibited worsening symptoms or radiological progression and zero $(0 \%)$ underwent repeat operations. Of 5 patients who initially underwent tonsillopexy, $2(40 \%)$ underwent repeat operations (both tonsillopexy) -1 for persistent headache and unchanged imaging and 1 for an expansile syrinx. One patient refused additional surgery for persistent dysphagia and headaches (but no syrinx). Of 2 patients who initially underwent duraplasty with tonsils untouched, 1 (50\%) underwent a repeat operation (tonsillopexy) for residual sleep apnea. Finally, of 14 patients who initially underwent dural splitting, 2 (14\%) underwent repeat procedures. One patient underwent tonsillopexy for persistent syrinx, and 1 patient underwent duraplasty for persistent headaches and tonsillar herniation. 
TABLE 6. Clinical characteristics of patients with syrinx at presentation

\begin{tabular}{|c|c|c|c|c|c|c|}
\hline Management & $\begin{array}{l}\text { Sex, Age at } \\
\text { Op (yrs) }\end{array}$ & $\begin{array}{l}\text { Tonsillar Descent } \\
(\mathrm{mm})^{*}\end{array}$ & Syrinx Levels & Predominant Symptoms & Syrinx Course $†$ & $\begin{array}{l}\text { Clinical } \\
\text { Course }\end{array}$ \\
\hline \multicolumn{7}{|l|}{ Conservative } \\
\hline & $\mathrm{F}, \mathrm{NA}$ & 9.6 & $\mathrm{C} 7-\mathrm{T} 1$ & Motor & UC & UC \\
\hline & $\mathrm{M}, \mathrm{NA}$ & 7.9 & $\mathrm{C} 4-\mathrm{T} 4$ & Headache & Incr & I \\
\hline \multicolumn{7}{|l|}{ Tonsillectomy } \\
\hline & $\mathrm{M}, 16.4$ & 37.0 & $\mathrm{C}-3$ & Headache, sleep apnea & $\mathrm{R}$ & 1 \\
\hline & $F, 14.0$ & 20.0 & C3-7 & Swallowing & $\mathrm{R}$ & I \\
\hline & M, 3.2 & 8.0 & $\mathrm{C} 4-\mathrm{T} 1$ & Incidental & I & 1 \\
\hline & $M, 16.8$ & 20.6 & C1-2 & Headache & $\mathrm{R}$ & 1 \\
\hline \multicolumn{7}{|l|}{ Tonsillopexy } \\
\hline & $\mathrm{F}, 11.0$ & 14.0 & $\mathrm{C} 2-7, \mathrm{~T} 2-3$ & Headache, visual & Incr & W \\
\hline & $F, 16.6$ & 12.0 & C4-T8 & Headache, sensory & Incr & W \\
\hline \multicolumn{7}{|l|}{ Tonsils untouched } \\
\hline & $\mathrm{F}, 4.2$ & 11.0 & $\mathrm{C} 5-\mathrm{T} 7$ & Headache, motor, swallowing & $\mathrm{R}$ & W \\
\hline \multicolumn{7}{|l|}{ Dural splitting } \\
\hline & $\mathrm{F}, 18.7$ & 29.0 & C2-7 & $\begin{array}{l}\text { Headache, visual, sensory, } \\
\text { swallowing }\end{array}$ & $\mathrm{R}$ & I \\
\hline & $F, 9.1$ & 15.0 & C3-T8 & Swallowing & 1 & I \\
\hline & $\mathrm{M}, 11.7$ & 24.0 & C2-5 & Headache, visual & I & W \\
\hline & M, 2.5 & 8.0 & T3-8 & Incidental & Slight decr & 1 \\
\hline & $F, 12.5$ & 14.0 & C3-T9 & Sleep apnea & $\mathrm{R}$ & I \\
\hline & $F, 16.3$ & 21.3 & C5-T4 & Headache & $\mathrm{R}$ & 1 \\
\hline & $F, 12.8$ & 19.0 & T6-10 & Headache, motor & $\mathrm{R}$ & I \\
\hline & $M, 5.6$ & 13.0 & C2-3 & Asymptomatic & $\mathrm{R}$ & I \\
\hline & $\mathrm{M}, 8.0$ & 11.0 & T4-9 & Headache & I & W \\
\hline
\end{tabular}

\section{Discussion}

In this study of a cohort of 116 pediatric patients diagnosed with CM-I over a 10 -year period, 95 patients were included in a final analysis: 70 patients were treated conservatively and followed with serial outpatient neurological and radiological examinations, whereas 25 patients were treated with PFD. Of these 25 surgical patients, 11 were treated with duraplasty (complete dural opening) and 14 were treated with a dura-splitting technique. Surgical intervention was associated with better clinical resolution of symptoms and radiological resolution of tonsillar ectopia and syringomyelia. Over the course of follow-up,

TABLE 7. CSF flow dynamics exhibited by cine MRI

\begin{tabular}{ccccccrrrrr}
\hline Management & No. of Pts & Normal & Abn & Abn Dors & Abn Vent & Exagg & Improved & Worsened & No Change & No FU \\
\hline Total & 74 & 20 & 54 & 49 & 18 & 25 & 11 & 4 & 11 \\
\hline Nonsurgical & 51 & 18 & 33 & 30 & 7 & 12 & 2 & 4 & 5 \\
\hline Surgical & 23 & 2 & 21 & 19 & 11 & 13 & 9 & 0 & 6 \\
\hline Duraplasty & 10 & 1 & 9 & 7 & 3 & 8 & 3 & 0 & 4 \\
\hline Tonsillectomy & 4 & 0 & 4 & 2 & 3 & 4 & 2 & 0 & 0 \\
\hline Tonsillopexy & 5 & 1 & 4 & 4 & 0 & 3 & 1 & 0 & 4 \\
\hline Tonsils untouched & 1 & 0 & 1 & 1 & 0 & 1 & 0 & 0 & 0 \\
\hline Dural splitting & 13 & 1 & 12 & 12 & 8 & 5 & 6 & 0 & 1 \\
\hline
\end{tabular}

$\mathrm{Abn}=$ abnormal cine MRI; abn dors = abnormal dorsal flow relative to foramen magnum; abn vent = abnormal ventral flow relative to foramen magnum; exagg = exaggerated cranial or caudal pulsations; no FU = patient did not receive additional cine MRI after initial study; pts = patients. 
20 of 48 nonsurgical patients who were symptomatic at presentation experienced improvement in symptoms, and 18 of 24 surgical patients showed clinical improvement $(\mathrm{p}=0.0117)$. One patient who underwent dural splitting was asymptomatic at presentation. In reference to surgical technique, there was no statistically significant difference in resolution of symptoms between duraplasty and durasplitting techniques $(p=0.3572)$ or between patients who underwent tonsillectomy and tonsillopexy $(p=0.1667)$, though this was likely secondary to the low study power of 7 surgical patients (Table 4). However, patients who underwent dural splitting had a shorter hospitalization and had fewer episodes of postoperative nausea.

These finding are consistent with the prevailing literature comparing more versus less invasive modes of Chiari decompression. In recent years, several neurosurgical series have compared extradural PFD to duraplasty with mixed evidence to suggest any significant difference in symptomatic outcome. ${ }^{17,19,22,23}$ To address study limitations of unbalanced demographics between treatment groups, presenting symptoms, and radiological findings, Lee and colleagues provided a balanced treatment comparison focusing on long-term clinical outcome and radiological syrinx improvement and proposed that extradural decompression for CM-I leads to comparable clinical and radiological improvement compared with traditional PFDD, but offers decreased postoperative morbidity. The authors recommended the more invasive PFDD as first-line treatment for more severe patients with rapidly progressive symptoms or severe neurological deficits. ${ }^{16}$ Our data echoes these results in that even though there was no difference with overall clinical outcome between the 2 techniques, patient who underwent dural splitting had a quicker and easier recovery.

The present study also revealed statistically significant differences in radiological findings over the followup period, chief among them the syrinx course between conservative and operative management (Tables 6 and 7). Eighteen patients had a syrinx at presentation. None of the nonsurgical patients showed syrinx improvement or resolution while well over half of surgical patients (65\%) showed complete resolution $(p=0.0149)$. Coupled with a statistically significant difference in tonsillar herniation, surgery was associated with better radiological outcomes than conservative management. Moreover, CSF flow dynamics as measured by cine MRI suggested that decompression significantly improved CSF flow over time when compared with conservative management $(p=0.05)$. These outcomes are believed to have resulted primarily from stringent qualifications for surgical candidates. As discussed above, all surgical patients were symptomatic, with either dysphagia or sleep apnea, had a syrinx, or had other neurological manifestations on examination. The conservative cohort had mostly nonspecific findings, such as non-Valsalvarelated frontal or temporal headaches, and had no definitive neurological signs. In addition, the nonsurgical cohort exhibited less tonsillar herniation (mean $10.4 \mathrm{~mm}$ ) than the surgical group (mean $18.8 \mathrm{~mm}$ ) at presentation. Therefore, the data from this study suggests the clinical value of a very careful selection process in identifying appropriate surgical candidates for PFD in CM-I patients.
The pathophysiological underpinnings of syrinx formation in children with CM-I has been previously descr ibed, $, 3,7,-11,15,18,20,21,26,38$ and the presence of a syrinx is considered an indication for surgical intervention at many neurosurgical centers. ${ }^{12-14} \mathrm{~A}$ recent meta review of 145 operative series of patients with CM-I (30\% of series included patients $\leq 18$ years of age) noted an incidence of syringomyelia of $65 \%$, which improved or resolved in $78 \%$ of patients. Most series reported improved postoperative neurological outcomes (75\%), whereas $17 \%$ showed no change and $9 \%$ experienced worsening. ${ }^{4}$ Despite only a few reports of the natural history of syrinx in the setting of CM-I, ${ }^{8,24}$ Schijman and Steinbok found that $75 \%$ of surveyed neurosurgeons would perform a suboccipital decompression for an asymptomatic patient with CM-I and a syrinx at least $8 \mathrm{~mm}$ in maximum diameter (28\% would intervene for a syrinx of $2 \mathrm{~mm}$ ). ${ }^{28}$ Strahle and colleagues followed 147 patients with MRI for 3.8 years and identified 13 patients known to have a spinal cord syrinx at the time of CM-I diagnosis, and whose syringes were managed without surgical intervention. The authors proposed that the presence of a syrinx was not always associated with symptomatic progression since only 6 of 20 patients with a syrinx had surgery during the follow-up interval, and 2 of these patients underwent surgery for reasons other than the syrinx ${ }^{31}$ Other investigators have added to the debate of surgery as necessary intervention in the setting of CM-I and syrinx. ${ }^{8,24}$ Nishizawa and colleagues found over a 10 year follow-up interval that only 1 of 9 adult patients with incidental CM-I and syrinx required decompression. They reported that 8 of 9 patients exhibited no significant change in the MRI characteristics. ${ }^{24}$ Beyond mere stability of syringes over time, there have been cases of regression and complete resolution, ${ }^{34-36}$ with the first spontaneous resolution of syrinx associated with CM-I reported by Sudo and colleagues in 1990 and 1994. ${ }^{32,33}$ Despite these studies, our data reveal that $69 \%$ of patients with a symptomatic syrinx who were treated with surgery showed clinical improvement. Of the patients who improved clinically, $100 \%$ had radiological syrinx improvement while only $60 \%$ of patients without symptomatic improvement had a smaller syrinx ( $p=0.0833)$. Even though this data does not reach statistical significance, this difference does suggest a correlation between improvement in syrinx size and symptoms.

The more salient findings of the present study suggest significant improvement in clinical and radiological outcomes of patients who received surgical management compared with those who received conservative management alone. Over the course of a 44.8-month radiological follow-up period, surgical patients exhibited a mean reduction of $54.8 \%$ in tonsillar herniation compared with a $10.6 \%$ reduction in the conservative group $(\mathrm{p}<0.0001)$ (Table 2). Over the course of a 66.3-month clinical followup period, $75 \%$ of surgical patients experienced resolution or improvement in symptoms compared with only $41.7 \%$ of conservatively managed patients who were symptomatic at presentation $(\mathrm{p}=0.0117)$ (Table 4). These differences lend credence to the utility of operating on symptomatic patients with significant radiological findings: 48 (69\%) of 70 nonsurgical patients were symptomatic at presentation, whereas $22(88 \%)$ of 25 surgical patients exhibited 
symptoms consistent with CM-I (Table 3). Of these surgical patients, $16(64 \%)$ presented with syrinx and $21(84 \%)$ presented with either syrinx or central sleep apnea. With regard to the clinical course of the 70 patients, the conservative group, 20 (28.6\%) exhibited improvement in symptoms, $45(64.3 \%)$ exhibited no change in symptoms, and 5 (7.1\%) exhibited worsening of symptoms. These findings are consistent with recent literature suggesting that the majority of patients with CM-I managed conservatively do not progress clinically or radiologically, and that pediatric patients not clearly symptomatic and without syrinx do not need prophylactic decompression, as the development of new symptoms and neurological deficits is uncommon. ${ }^{6}$

When compared with previous studies, the present study has several strengths, chief among them the number of patients and longitudinal nature of follow-up. Comprehensive neurological and radiological examinations were instrumental in confirming prospective diagnoses of CM-I and concurrent syringomyelia as well as identifying appropriate surgical candidates. However, this study is not without limitations. This is a single-center analysis and thereby reflects the treatment bias of our institution. Like earlier reports, the retrospective nature of this study, combined with a limited number of treating surgeons, may increase the potential for bias in data collection and decrease the generalizability of results. As a unique benefit, however, one senior surgeon performing all operations increases consistency in clinical and operative decision-making. To help control for a single neurosurgeon selection bias, our institution has a multidisciplinary pediatric group with recurring case conferences and film reviews.

Going forward, longitudinal follow-up studies with special emphasis on patients with either neurological deficits or severe symptoms, despite widespread acceptance of decompression in these patients, will help to further elucidate the natural history of CM-I and more appropriately gauge the risk-benefit tradeoff of a growing spectrum of surgical interventions. With further study over longer time horizons meant to capture all cases of clinical and/or radiological deterioration, we may further be able to refine diagnostic criteria, predict symptomatic progression, and, accordingly, match appropriate surgical and nonsurgical therapeutic modalities to patient functioning.

\section{Conclusions}

CM-I patients managed conservatively do not show significant clinical or radiological progression. However, symptomatic patients (sleep apnea and dysphagia) presenting with tonsillar herniation and syrinx should be given serious consideration as surgical candidates for they can show significant clinical and radiological improvement after surgery.

\section{References}

1. Aboulezz AO, Sartor K, Geyer CA, Gado MH: Position of cerebellar tonsils in the normal population and in patients with Chiari malformation: a quantitative approach with MR imaging. J Comput Assist Tomogr 9:1033-1036, 1985

2. Aitken LA, Lindan CE, Sidney S, Gupta N, Barkovich AJ, Sorel M, et al: Chiari type I malformation in a pediatric population. Pediatr Neurol 40:449-454, 2009
3. Armonda RA, Citrin CM, Foley KT, Ellenbogen RG: Quantitative cine-mode magnetic resonance imaging of Chiari I malformations: an analysis of cerebrospinal fluid dynamics. Neurosurgery 35:214-224, 1994

4. Arnautovic A, Splavski B, Boop FA, Arnautovic KI: Pediatric and adult Chiari malformation Type I surgical series 1965-2013: a review of demographics, operative treatment, and outcomes. J Neurosurg Pediatr 15:161-177, 2015

5. Barkovich AJ, Wippold FJ, Sherman JL, Citrin CM: Significance of cerebellar tonsillar position on MR. AJNR Am J Neuroradiol 7:795-799, 1986

6. Benglis D Jr, Covington D, Bhatia R, Bhatia S, Elhammady MS, Ragheb J, et al: Outcomes in pediatric patients with Chiari malformation Type I followed up without surgery. J Neurosurg Pediatr 7:375-379, 2011

7. Blagodatsky MD, Larionov SN, Manohin PA, Shanturov VA, Gladyshev YV: Surgical treatment of "hindbrain related" syringomyelia: new data for pathogenesis. Acta Neurochir (Wien) 124:82-85, 1993

8. Bogdanov EI, Mendelevich EG: Syrinx size and duration of symptoms predict the pace of progressive myelopathy: retrospective analysis of 103 unoperated cases with craniocervical junction malformations and syringomyelia. Clin Neurol Neurosurg 104:90-97, 2002

9. Cahan LD, Bentson JR: Considerations in the diagnosis and treatment of syringomyelia and the Chiari malformation. J Neurosurg 57:24-31, 1982

10. Eule JM, Erickson MA, O'Brien MF, Handler M: Chiari I malformation associated with syringomyelia and scoliosis: a twenty-year review of surgical and nonsurgical treatment in a pediatric population. Spine (Phila Pa 1976) 27:1451-1455, 2002

11. Greitz D: Unraveling the riddle of syringomyelia. Neurosurg Rev 29:251-264, 2006

12. Haines SJ, Berger M: Current treatment of Chiari malformations types I and II: A survey of the Pediatric Section of the American Association of Neurological Surgeons. Neurosurgery 28:353-357, 1991

13. Haroun RI, Guarnieri M, Meadow JJ, Kraut M, Carson BS: Current opinions for the treatment of syringomyelia and chiari malformations: survey of the Pediatric Section of the American Association of Neurological Surgeons. Pediatr Neurosurg 33:311-317, 2000

14. Hida K, Iwasaki Y, Koyanagi I, Abe H: Pediatric syringomyelia with chiari malformation: its clinical characteristics and surgical outcomes. Surg Neurol 51:383-391, 1999

15. Holly LT, Batzdorf U: Syringomyelia associated with intradural arachnoid cysts. J Neurosurg Spine 5:111-116, 2006

16. Lee A, Yarbrough CK, Greenberg JK, Barber J, Limbrick DD, Smyth MD: Comparison of posterior fossa decompression with or without duraplasty in children with Type I Chiari malformation. Childs Nerv Syst 30:1419-1424, 2014

17. Limonadi FM, Selden NR: Dura-splitting decompression of the craniocervical junction: reduced operative time, hospital stay, and cost with equivalent early outcome. J Neurosurg 101 (2 Suppl):184-188, 2004

18. Lipson AC, Ellenbogen RG, Avellino AM: Radiographic formation and progression of cervical syringomyelia in a child with untreated Chiari I malformation. Pediatr Neurosurg 44:221-223, 2008

19. McGirt MJ, Attenello FJ, Datoo G, Gathinji M, Atiba A, Weingart JD, et al: Intraoperative ultrasonography as a guide to patient selection for duraplasty after suboccipital decompression in children with Chiari malformation Type I. J Neurosurg Pediatr 2:52-57, 2008

20. Menezes AH: Chiari I malformations and hydromyeliacomplications. Pediatr Neurosurg 17:146-154, 1991-1992

21. Milhorat TH, Capocelli AL Jr, Anzil AP, Kotzen RM, Milhorat RH: Pathological basis of spinal cord cavitation in 
syringomyelia: analysis of 105 autopsy cases. J Neurosurg 82:802-812, 1995

22. Munshi I, Frim D, Stine-Reyes R, Weir BK, Hekmatpanah J, Brown F: Effects of posterior fossa decompression with and without duraplasty on Chiari malformation-associated hydromyelia. Neurosurgery 46:1384-1390, 2000

23. Navarro R, Olavarria G, Seshadri R, Gonzales-Portillo G, McLone DG, Tomita T: Surgical results of posterior fossa decompression for patients with Chiari I malformation. Childs Nerv Syst 20:349-356, 2004

24. Nishizawa S, Yokoyama T, Yokota N, Tokuyama T, Ohta S: Incidentally identified syringomyelia associated with Chiari I malformations: is early interventional surgery necessary? Neurosurgery 49:637-641, 2001

25. Novegno F, Caldarelli M, Massa A, Chieffo D, Massimi L, Pettorini B, et al: The natural history of the Chiari Type I anomaly. J Neurosurg Pediatr 2:179-187, 2008

26. Oldfield EH, Muraszko K, Shawker TH, Patronas NJ: Pathophysiology of syringomyelia associated with Chiari I malformation of the cerebellar tonsils. Implications for diagnosis and treatment. J Neurosurg 80:3-15, 1994

27. Schijman E: History, anatomic forms, and pathogenesis of Chiari I malformations. Childs Nerv Syst 20:323-328, 2004

28. Schijman E, Steinbok P: International survey on the management of Chiari I malformation and syringomyelia. Childs Nerv Syst 20:341-348, 2004

29. Speer MC, George TM, Enterline DS, Franklin A, Wolpert CM, Milhorat TH: A genetic hypothesis for Chiari I malformation with or without syringomyelia. Neurosurg Focus 8(3):E12, 2000

30. Steinbok P: Clinical features of Chiari I malformations. Childs Nerv Syst 20:329-331, 2004

31. Strahle J, Muraszko KM, Kapurch J, Bapuraj JR, Garton HJ, Maher CO: Natural history of Chiari malformation Type I following decision for conservative treatment. J Neurosurg Pediatr 8:214-221, 2011

32. Sudo K, Doi S, Maruo Y, Tashiro K, Terae S, Miyasaka K, et al: Syringomyelia with spontaneous resolution. J Neurol Neurosurg Psychiatry 53:437-438, 1990

33. Sudo K, Tashiro K, Isu T: Spontaneous drainage in syringomyelia. J Neurosurg 80:950-951, 1994
34. Sun JC, Steinbok P, Cochrane DD: Spontaneous resolution and recurrence of a Chiari I malformation and associated syringomyelia. Case report. J Neurosurg 92 (2 Suppl):207-210, 2000

35. Sun PP, Harrop J, Sutton LN, Younkin D: Complete spontaneous resolution of childhood Chiari I malformation and associated syringomyelia. Pediatrics 107:182-184, 2001

36. Tokunaga M, Minami S, Isobe $\mathrm{K}$, Moriya $\mathrm{H}$, Kitahara $\mathrm{H}$, Nakata Y: Natural history of scoliosis in children with syringomyelia. J Bone Joint Surg Br 83:371-376, 2001

37. Tubbs RS, Lyerly MJ, Loukas M, Shoja MM, Oakes WJ: The pediatric Chiari I malformation: a review. Childs Nerv Syst 23:1239-1250, 2007

38. Wetjen NM, Heiss JD, Oldfield EH: Time course of syringomyelia resolution following decompression of Chiari malformation Type I. J Neurosurg Pediatr 1:118-123, 2008

39. Wu YW, Chin CT, Chan KM, Barkovich AJ, Ferriero DM: Pediatric Chiari I malformations: do clinical and radiologic features correlate? Neurology 53:1271-1276, 1999

\section{Disclosures}

The authors report no conflict of interest concerning the materials or methods used in this study or the findings specified in this paper.

\section{Author Contributions}

Conception and design: Pomeraniec, Ksendzovsky, Jane. Acquisition of data: all authors. Analysis and interpretation of data: all authors. Drafting the article: all authors. Critically revising the article: all authors. Reviewed submitted version of manuscript: all authors. Approved the final version of the manuscript on behalf of all authors: Pomeraniec. Statistical analysis: Pomeraniec, Ksendzovsky, Jane. Administrative/technical/material support: Pomeraniec, Ksendzovsky, Jane. Study supervision: Pomeraniec, Ksendzovsky, Jane.

\section{Correspondence}

I. Jonathan Pomeraniec, Department of Neurosurgery, University of Virginia Health Sciences Center, Box 800212, Charlottesville, VA 22908. email: ijp3by@virginia.edu. 